\title{
The role of emotional intelligence and work engagement on nurses' resilience in public hospitals
}

\begin{tabular}{|c|c|}
\hline \multicolumn{2}{|c|}{$\begin{array}{l}\text { Authors: } \\
\text { Pardon Chikobvu }{ }^{1} \text { (] } \\
\text { Martha Harunavamwe }\end{array}$} \\
\hline \multicolumn{2}{|c|}{$\begin{array}{l}\text { Affiliations: } \\
{ }^{1} \text { Department of Industrial } \\
\text { Psychology, Faculty of } \\
\text { Economic Management } \\
\text { Sciences, University of the } \\
\text { Free State, Bloemfontein, } \\
\text { South Africa }\end{array}$} \\
\hline \multicolumn{2}{|c|}{$\begin{array}{l}\text { Corresponding author: } \\
\text { Martha Harunavamwe, } \\
\text { harunavamweM@ufs.ac.za }\end{array}$} \\
\hline \multicolumn{2}{|c|}{$\begin{array}{l}\text { Dates: } \\
\text { Received: } 02 \text { June } 2021 \\
\text { Accepted: } 18 \text { Jan. } 2022 \\
\text { Published: } 28 \text { Feb. } 2022\end{array}$} \\
\hline \multicolumn{2}{|c|}{$\begin{array}{l}\text { How to cite this article: } \\
\text { Chikobvu, P., \& } \\
\text { Harunavamwe, M. (2022). } \\
\text { The role of emotional } \\
\text { intelligence and work } \\
\text { engagement on nurses' } \\
\text { resilience in public hospitals. } \\
\text { SA Journal of Human } \\
\text { Resource Management/SA } \\
\text { Tydskrif vir } \\
\text { Menslikehulpbronbestuur, } \\
\text { 20(0), a1690. https://doi. } \\
\text { org/10.4102/sajhrm. } \\
\text { v20i0.1690 }\end{array}$} \\
\hline \multicolumn{2}{|c|}{$\begin{array}{l}\text { Copyright: } \\
\text { (c) 2022. The Authors. } \\
\text { Licensee: AOSIS. This work } \\
\text { is licensed under the } \\
\text { Creative Commons } \\
\text { Attribution License. }\end{array}$} \\
\hline \multicolumn{2}{|c|}{ Read online: } \\
\hline 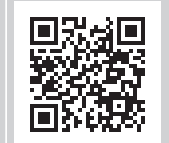 & $\begin{array}{l}\text { Scan this QR } \\
\text { code with your } \\
\text { smart phone or } \\
\text { mobile device } \\
\text { to read online. }\end{array}$ \\
\hline
\end{tabular}

Orientation: The ability to cope effectively with adversity has become vital for healthcare employees because of high job demands. Nurses are faced with workplace adversities that drain resilience resources; as such it is important to investigate factors that may conserve and build resilience resources. Positive states in the form of emotional intelligence and engagement have the potential to activate and conserve resources for coping and adaption amongst nurses.

Research purpose: The study was designed to investigate empirically the predictive value of emotional intelligence and work engagement on nurses' resilience.

Motivation for the study: The study was motivated by the fact that negative experiences or adversities kindle loss of resources for coping and adaptive functioning. Promoting positive states has the potential to motivate the building of resources that improve coping and adaptation.

Research approach, design and method: The study utilised a cross-sectional quantitative survey using self-administered questionnaires. The sample comprised 252 nurses from the Mangaung Metropole, South Africa. The SmartPLS programme was used to analyse the data.

Main findings: Emotional intelligence and work engagement had a statistically significant effect on resilience. Of great significance was the strong direct link between emotional intelligence and resilience.

Practical or managerial implication: The healthcare sector needs to invest training in emotional intelligence and work engagement programmes for nurses as a way to improve their resilience; a coping strategy for the highly demanding and stressful work environments.

Contribution: These findings contribute valuable new knowledge that can be applied in promoting and enhancing resilience of nurses in public hospitals.

Keywords: resilience; work engagement; emotional intelligence; nurse in the public hospitals, personal resources, work overload.

\section{Introduction}

As a result of the highly demanding nature of the nursing profession, resilience has become one of the most critical attributes for healthcare workers in public hospitals (Duncan, 2020). Resilience fosters nurses to maintain professional integrity and continues to provide safe and effective care (Best, 2019). Ramalisa, Du Plessis and Koen (2018) indicated that South African nurses face adversities in their working environment, which leaves them feeling demotivated, angry and dissatisfied. Khamisa, Peltzer, Ilic and Oldenburg (2017) commented that nurses' work environment is characterised by high acuity and long hours, workplace violence, abuse, bullying and sexual harassment. Koen, Van Eeden and Wissing (2011) added that nurses are exposed to the suffering of human beings, death and grief, which leaves them feeling emotionally drained. In addition to emotional fatigue, nurses experience psychological emptiness, diminishing inner balance and a sense of dissonance, which depreciates their ability to be resilient (Hart, Brannan, \& Chesnay, 2014). Likewise, Hobfoll et al. (2015) argued that these workplace adversities cause severe resource loss, which greatly undermines resilience building. The fact that employees are still suffering from the negative effects of workplace adversities questions the efficacy of the strategies currently used to improve resilience. Based on that, managers or practitioners are faced with a task of finding alternative ways to improve resilience of employees in order to improve efficiency and overall organisational performance. 
Resilience has been positively associated with personal and organisational outputs, such as skills improvement and job and life satisfaction amongst nurses (Duncan, 2020). In addition, it has also been associated with retention and reduction in the sense of exhaustion and psychological problems (i.e. depression) and better patient care (Çam \& Buyukbayram, 2017). In South Africa, resilience is recognised as an important characteristic and resource for employees (Meintjes \& Hofmeyr, 2018; Ramalisa et al., 2018). It is reported that resilience has a positive impact on nurses' health and life, improves quality of services, and reduces the cost of healthcare (Koen et al., 2011; Ramalisa et al., 2018; Salilih \& Abajobir, 2014). Despite the efforts made to improve resilience, nurses in South Africa are still affected by heavy work overloads, poor work relationships, as well as mental, emotional and physical exhaustion, which negatively affect their well-being and persistently diminish their resilience (Khamisa et al., 2017; Truter, Theron, \& Fouché, 2014). Ramalisa et al. (2018) and Koen et al. (2011) observed that the declining levels of resilience may be attributed to ineffective strategies implemented to promote resilience; therefore it is worth exploring the role of emotional intelligence and work engagement on nurses' resilience in the public hospitals.

A combination of negative experiences and workplace adversities are argued to be the main ingredients for the mental and psychological illness that threatens the resilience of employees (McDermid, Peters, Daly, \& Jackson, 2016). This can be neutralised by positive states or positive mindsets, which in turn promote and strengthen resilience. Correspondingly, Pidgeon, Ford and Klaassen (2014) comment that positive perceptions and attitudes are necessary for individuals to effectively function and cope despite facing challenges and or adversities. Moreover, scholars (e.g. Hakanen, Perhoniemi, \& Toppinen-Tanner, 2008; Hobfoll et al., 2015) agree that positive states cluster together resulting in resource gain and enhancing resilience. A number of positive states (e.g. self-efficacy, hope, emotional intelligence, positive outlook, optimism, work satisfaction and spirituality) have been identified as antecedents to resilience (Çam \& Buyukbayram, 2017; Hart et al., 2014; Yilmaz, 2017). This study focused on emotional intelligence and work engagement as possible ways to activate and conserve resources for coping and adaption amongst nurses. Therefore, this study seeks to determine the role of emotional intelligence and work engagement amongst nurses in the public hospitals.

\section{Research purpose and objectives}

The primary aim of the study is to determine the role of emotional intelligence and work engagement on the resilience of nurses in the public hospitals. To this effect the following research objectives were formulated:

- To establish the influence of emotional intelligence on resilience.

- To determine the combined influence of emotional intelligence and work engagement on resilience.
- To determine the mediating effect of work engagement in the relationship between emotional intelligence and resilience.

\section{Literature review}

Resilience has its roots in the practice of positive organisational behaviour, which focuses on positive human resource strength and psychological capacities for the improvement of workplace performance (Crane, 2017). For this study, resilience was approached from Wagnild and Young's (1993) point of views. They conceptualised it as an individual's adaptive capacity having the interrelated characteristics of equanimity, perseverance, self-reliance, meaningfulness and existential aloneness. Equanimity is the first step in resilience and it refers to having a balanced perspective of one's life and experiences. Perseverance refers to the drive to persist in the face of challenges (Aiena, Baczwaski, Schulenberg, \& Buchanan, 2014). Thirdly, self-reliance refers to a belief in oneself and one's capacities (Paul, Bamel, \& Garg, 2016). Meaningfulness connotes having a sense of purpose and long-term goals (Wagnild \& Young, 1993). Lastly, existential aloneness refers to a belief and realisation that every person has a different path in life (Paul et al., 2016). Aiena et al. (2014) presented that existential aloneness occurs when individuals are comfortable with themselves and with handling things on their own.

Pidgeon et al. (2014) argued that resilience is subject to influences from environmental, work-specific and personal contexts. This implies that the ability to demonstrate resilience depends on one's experience and perceived experiences. Resilience is regarded as a source of competitive advantage for organisations as it has implications for promoting individual competences, enhancing individual responses to stressful circumstances and improving job performance (Zhu, Zhang, \& Shen, 2019). As highlighted earlier, a number of positive states have been reported as antecedents to resilience. For the purpose of this study the positive states identified to influence resilience is limited to emotional intelligence and work engagement.

\section{Emotional intelligence and resilience}

The concept of emotional intelligence dates back to the works of Charles Darwin (1872/1965) on emotional expression in survival and adaptation (Prins, Van Niekerk, \& Weyers, 2018). The current widespread interest in the concept is attributed to the growing importance of positive psychological states and flourishing in the workplace. Emotional intelligence was approached from Goleman's (1995) perspective, who defines it as the ability to recognise and regulate emotions in oneself and in others in order to achieve successful work performance. In this definition, Goleman (1995) identified five components that include self-awareness, self-regulation, motivation, empathy and social skills (Toyama \& Mauno, 2017). Emotional intelligence enables individuals to accurately assess their environment, express empathy and think according to the priority of problems and 
organise thoughts, which consequently increases resilience (Magnano, Craparo, \& Paolillo, 2016):

Hypothesis 1: Emotional intelligence (self-awareness, selfregulation, motivation, empathy and social skills) has a positive influence on resilience.

\section{Work engagement and resilience}

Work engagement has its roots in burnout literature and it emerged as an attempt to shift from employee unwell-being to employee well-being (Albrecht, 2010; Bakker et al., 2008). Schaufeli, Salanova, Romá and Bakker (2002) defined work engagement as a positive, fulfilling work-related state of mind characterised by full concentration in one's work and having high levels of energy and enthusiasm whilst working. Thus, work engagement is characterised by vigour, dedication and absorption. Bakker and Leiter (2010) argued that work engagement is an important strategy for organisations as it may contribute to the physical, emotional and mental well-being of employees. Engaged employees display positive attitudes towards their work, commit emotionally to their work and are likely to be mentally absorbed in their work. As a motivational concept, engagement is argued to be related to the persistence and intensity with which individuals pursue their task performance (Kašpárková, Vaculík, Procházk, \& Schaufeli, 2018; Rich, Lepine, \& Crawford, 2010). In other words, work engagement influences resilience:

Hypothesis 2: Emotional intelligence and work engagement influence resilience.

\section{Relationship between emotional intelligence, work engagement and resilience}

Ackley (2016) and Antoniou and Cooper (2016) agreed that individuals will not be able to bounce back or engage if they do not have an accurate assessment of the environment in which they are operating. Prins et al. (2018) stated that emotionally intelligent individuals, through their excellent self-awareness, are much more aware of what happens in their surroundings. Prins et al. (2018) further commented that emotionally intelligent individuals, through their ability to manage their emotions well, have motivation and experience positive emotions. The experience of positive affect fuels the investment of more energy, which is salient in the development of positive job attitudes such as work engagement (Salanova, Schaufeli, Xanthopoulou, \& Bakker, 2010). Van Wingerden and Poell (2019) indicated that:

[E]ngaged employees create their own great place as they are able to craft their work. By doing so, they optimize their work environment in a way that it is aligned with their preferences and abilities which subsequently strengthens their resilience. (p. 2)

From the foregoing discussion, emotional intelligence is the point of entry of the proposed relationship (between emotional intelligence, work engagement and resilience). It also suggests that work engagement mediates the relationship between emotional intelligence and resilience.
Hypothesis 3: Work engagement mediates the relationship between emotional intelligence and resilience.

\section{Research design Research approach}

The study utilised a quantitative approach that is rooted in the positivist paradigm. As the study involved validation, hypothesis testing and describing relationships between the independent variables (work engagement and emotional intelligence) and the dependent variable (resilience), the quantitative approach was most appropriate. Specifically, the study employed a cross-sectional survey as the researcher wanted to obtain an overall picture of a phenomena at a specific point in time.

\section{Research method \\ Research participants}

The target population of the study was nursing employees working in the Mangaung Metropole, South Africa. Nurses from three selected public hospitals (Pelonomi, Botshabelo and National), with a total population of 938 , were chosen for the study. Although 335 questionnaires were distributed, only 282 were returned and of those returned 252 were eligible to be captured for analysis. Thus, the study had a response rate of $75.2 \%$.

Nurses between the ages of 41 and 50 years constituted the largest group within the sample (31.3\%) whilst the majority of the nurses surveyed were females (80.2\%). Most of the respondents were from the medical nursing department, constituting $28.6 \%$ of the sample. The highest level of education achieved by the nurses who participated was an advanced diploma (23.8\%). Only a few nursing employees had undergraduate $(5.6 \%)$ and postgraduate degree qualifications (15.1\%). Most participants (23.8\%) had 6-10 years' experience in their current organisation.

\section{Measuring instrument}

The measuring instrument had four sections. The first section was a biographical questionnaire. The other sections consisted of pre-established scales, namely the Utrecht Work Engagement Scale (Section B), Rahim Emotional Quotient Index (Rahim et al., 2002) (Section C) and the Wagnild and Young Resilience Scale (Section D).

The 14-item resilience scale (RS-14) (Wagnild \& Young, 1993) was used to assess nurses' resilience. The scale is based on five dimensions, namely perseverance, equanimity, selfreliance, meaningfulness and existential aloneness. All items were scored on a 7-point Likert scale that ranges from $1=$ disagree to 7 = agree. Koen et al. (2011), in a South African sample, reported acceptable reliability score for the scale with a Cronbach's alpha coefficient of 0.80 and test-retest coefficients of $0.60-0.98$. Koen et al. (2011) commented that the construct validity of the measuring instrument indicate 
that the scale is valid. In this study, an acceptable internal consistency score of $\alpha=0.889$ was obtained.

Work engagement was measured using the Utrecht Work Engagement Scale (UWES)-17 (Schaufeli \& Bakker, 2004). The scale is made up of 17 items loading on three factors, namely vigour, dedication and absorption. Responses were scored on a 7-point Likert scale, ranging from $0=$ never to 6 = always. Schaufeli and Bakker (2004) reported an acceptable reliability coefficient for the scale as $\alpha=0.86$. In a South African study, Simons and Buitendach (2013) obtained the following alpha coefficients for the three subcomponents: vigour $(\alpha=0.90)$, dedication $(\alpha=0.86)$ and absorption $(\alpha=0.85)$. Simons and Buitendach (2013) found no evidence of item bias on the measure in the various race groups. In the present study, an acceptable internal consistency was observed for the three subscales: vigour $(\alpha=0.776)$, dedication $(\alpha=0.840)$ and absorption $(\alpha=0.798)$.

The Rahim Emotional Quotient Index (EQI) (Rahim et al., 2002) was used to measure the nurses' emotional intelligence. The instrument is made up of 22 items consisting of five factors, namely self-regulation, self-awareness, empathy, motivation and social skills. The instrument uses a 7-point Likert scale $(1=$ strongly disagree to $7=$ strongly agree). In a South African sample, Nel, Du Plessis and Bosman (2015), reported internal consistency reliability coefficients of the five subscales ranging between 0.844 and 0.994 . Nel et al. (2015) commented that the instrument is standardised and valid for the South African population. In this study, the following reliability scores were observed for the five subscales: self-awareness $(\alpha=0.810)$, self-regulation ( $\alpha=0.763)$, empathy $(\alpha=0.733)$, motivation $(\alpha=0.820)$ and social skills $(\alpha=0.705)$.

\section{Research procedure}

The research procedure was in accordance with the University of the Free State Health Sciences Research Ethics Committee (UFS_HSREC) with reference number UFSHDS2019/0077/2506. After being granted permission, the researcher was personally responsible for the distribution and collection of the questionnaires. Voluntary participation, anonymity and confidentiality were guaranteed.

\section{Statistical analysis}

Statistical analysis was conducted using the Statistical Package for the Social Sciences (SPSS) version 24, Lisrel 10.0 and Smart PLS. Descriptive statistics and statistical modelling were used to sum up the collected data and test the study's hypotheses. The Cronbach's alpha was used to assess the internal consistency reliability of the measuring instruments. Confirmatory factor analysis (CFA) through assessment of the goodness of fit statistics (CFI, RMSEA and SRMR) was used to determine the psychometric properties of the measuring instruments. Variance-based structural equation modelling (SEM) Smart PLS was used to test the direct and indirect links between emotional intelligence, work engagement and resilience.
The model was tested following the application of a two-step process, including (1) the assessment of the outer model then (2) the assessment of the inner model.

The outer model (i.e. measurement model) was evaluated in terms of internal consistency (composite reliability), convergent (average variance extracted [AVE] scores) and discriminant validity (heterotrait-monotrait ratio [HTMT] values). The outer model aimed to determine whether the measurements used to operationalise each of the latent variables were reliable and valid. The quality criteria associated with an acceptable outer model are: (1) AVE of 0.5 and higher, (2) composite reliability estimates of 0.7 and higher and (3) HTMT correlations cut-off score of 0.90 (Hair, Risher, Sarstedt, \& Ringle, 2019). The inner model (i.e. structural model) was evaluated using the following guidelines: (1) the size of the path coefficients (beta values), (2) significance of the path coefficients and (3) the amount of variance explained in the dependent variable by the proposed model.

\section{Ethical considerations}

Ethical clearance to conduct this study was obtained from the University of the Free State: UFS-HSD2019/0077/2506.

\section{Results}

\section{Validity and reliability of the scales}

Confirmatory factor analysis through the goodness of fit statistics confirmed the distinctive validity of emotional intelligence, work engagement and resilience. Cronbach's alpha coefficient and composite reliability was used to assess the reliability of the measuring instruments.

The resilience scale scored 0.899 Cronbach's alpha which is regarded as good Pallant (2013). The internal consistency of the emotional intelligence scale (measured by the Rahim EQI) consisting of five dimensions was good, ranging from 0.705 for social skills to 0.820 for motivation. The reliability scores associated with work engagement dimensions may be regarded as good (vigour $=0.776$, dedication $=0.840$, absorption $=0.798$ ).

Table 2 presents the goodness of fit statistics related to all the scales. The fit indices of the CFA model related to emotional

\begin{tabular}{lcc} 
TABLE 1: Reliability of the scales. & & \\
\hline Scale & Number of items & Cronbach's alpha \\
\hline Resilience & $\mathbf{1 4}$ & $\mathbf{0 . 8 8 9}$ \\
Vigour & 6 & 0.776 \\
Dedication & 5 & 0.840 \\
Absorption & 6 & 0.798 \\
Work engagement (Total) & $\mathbf{1 7}$ & $\mathbf{0 . 9 1 6}$ \\
Self-awareness & 4 & 0.810 \\
Self-regulation & 5 & 0.763 \\
Empathy & 4 & 0.733 \\
Motivation & 5 & 0.820 \\
Social skills & 4 & 0.705 \\
Emotional intelligence (Total) & $\mathbf{2 2}$ & $\mathbf{0 . 9 3 4}$
\end{tabular}


TABLE 2: Goodness of fit statistics.

\begin{tabular}{lcccccc}
\hline Variables & EI & $\boldsymbol{p}$ & RES & $\boldsymbol{p}$ & WE & $\boldsymbol{p}$ \\
\hline S-B $\chi 2$ & 312.788 & 0.0000 & 100.811 & 0.0048 & 273.765 & 0.0000 \\
Df & 199 & - & 67 & - & 116 & - \\
CFI & 0.966 & - & 0.984 & - & 0.930 & - \\
RMSEA & 0.134 & $0.126 ; 0.143$ & 0.190 & $0.176 ; 0.204$ & 0.132 & $0.12 ; 0.143$ \\
SRMR & 0.0863 & - & 0.0919 & - & 0.0718 & - \\
\hline
\end{tabular}

El, emotional intelligence; RES, resilience; WE, work engagement; $\mathrm{CFI}$, Comparative fit index RMSEA, Root mean square error of approximation; SRMR, Standardised root mean square residual; Df, Degrees of freedom.

TABLE 3: Quality criteria.

\begin{tabular}{lcccc}
\hline Variables & $\begin{array}{c}\text { Cronbach's } \\
\text { alpha }\end{array}$ & rho_A & $\begin{array}{c}\text { Composite } \\
\text { reliability }\end{array}$ & $\begin{array}{c}\text { Average variance } \\
\text { extracted (AVE) }\end{array}$ \\
\hline Emotional intelligence & 0.900 & 0.905 & 0.926 & 0.715 \\
Resilience & 0.880 & 0.890 & 0.912 & 0.675 \\
Work engagement & 0.879 & 0.879 & 0.925 & 0.805 \\
\hline
\end{tabular}

TABLE 4: Heterotrait-Monotrait ratio.

\begin{tabular}{lccc}
\hline Variables & $\begin{array}{c}\text { Emotional } \\
\text { intelligence }\end{array}$ & Resilience & Work engagement \\
\hline Emotional intelligence & - & - & - \\
Resilience & 0.768 & - & - \\
Work engagement & 0.575 & 0.516 & - \\
\hline
\end{tabular}

intelligence were reported as follows: CFI (0.966), RMSEA (0.134) and SRMR (0.0863). The model fitted the data well as two (CFA and SRMR) of the three fit statistics were acceptable. Goodness of fit results for work engagement were found as follows: CFI $=0.930$, RMSEA $=0.132$, SRMR $=0.0718$. Resilience observed the following goodness of fit indices: $\mathrm{CFI}=0.984, \mathrm{RMSEA}=0.190, \mathrm{SRMR}=0.0919$ ). The model was well fitting given that two of the three fit statistics (CFI and SRMR) were acceptable.

The composite reliability was used to compute the internal consistency reliability. The composite reliability scores for all three variables were above the cut-off score of 0.6. Thus, the three variables observed satisfactory composite reliability scores: emotional intelligence (0.926), resilience (0.912) and work engagement (0.925). The convergent validity of the measuring instruments in the measurement model assessed through the AVE score was also good. The AVE scores were above 0.5 (emotional intelligence $=0.715$, work engagement $=0.805$, resilience $=0.675$ )

Table 4 presents the results for discriminant validity. The following HTMT values were recorded for the constructs: resilience and work engagement (0.516), resilience and emotional intelligence (0.705), emotional intelligence and work engagement (0.575). To achieve discriminant validity, the HTMT values should be lower than 0.90 (Hair et al., 2019). This enabled the researcher of the present study to continue evaluating the inner model, representing the hypothesised model.

Table 5 presents the outer loadings that are the paths connecting each indicator to its respective construct. All the indicators loaded significantly on their respective constructs $(p=0.000)$. The indicator loadings ranged between 0.777 (existential aloneness) to 0.912 (vigour).
TABLE 5: Outer loadings.

\begin{tabular}{lcccc}
\hline Variables & $\begin{array}{c}\text { Factor } \\
\text { loadings }\end{array}$ & $\begin{array}{c}\text { Standard } \\
\text { deviation (s.d.) }\end{array}$ & $\begin{array}{c}\boldsymbol{T} \text { statistics } \\
(\mid \mathbf{O} / \text { s.d.|) }\end{array}$ & $\boldsymbol{p}$ \\
\hline Equanimity : Resilience & 0.797 & 0.034 & 23.552 & 0.000 \\
Existential aloneness : Resilience & 0.777 & 0.037 & 20.991 & 0.000 \\
Meaningfulness : Resilience & 0.848 & 0.022 & 39.185 & 0.000 \\
Perseverance : Resilience & 0.816 & 0.036 & 22.986 & 0.000 \\
Self-reliance : Resilience & 0.866 & 0.016 & 55.122 & 0.000 \\
Absorption : Work engagement & 0.906 & 0.016 & 57.792 & 0.000 \\
Dedication : Work engagement & 0.873 & 0.027 & 32.090 & 0.000 \\
Vigour : Work engagement & 0.912 & 0.013 & 72.104 & 0.000 \\
Empathy : Emotional intelligence & 0.839 & 0.023 & 36.171 & 0.000 \\
Motivation : Emotional intelligence & 0.844 & 0.025 & 34.162 & 0.000 \\
Self-awareness : Emotional & 0.784 & 0.032 & 24.156 & 0.000 \\
intelligence & & & & \\
Self-regulation : Emotional & 0.886 & 0.016 & 56.351 & 0.000 \\
intelligence & & & & \\
Social skills : Emotional intelligence & 0.872 & 0.019 & 45.705 & 0.000 \\
\hline
\end{tabular}

TABLE 6: Path coefficients (inner model).

\begin{tabular}{lccccc}
\hline Variables & $\begin{array}{c}\text { Original } \\
\text { sample (O) }\end{array}$ & $\begin{array}{c}\text { Sample mean } \\
\text { (M) }\end{array}$ & $\begin{array}{c}\text { Standard } \\
\text { deviation (s.d.) }\end{array}$ & $\begin{array}{c}\text { T statistics } \\
\text { (|O/s.d.) }\end{array}$ & $\boldsymbol{p}$ \\
\hline WE -> RES & 0.142 & 0.139 & 0.064 & 2.222 & 0.027 \\
EI -> WE & 0.516 & 0.519 & 0.046 & 11.189 & 0.000 \\
EI -> RE & 0.619 & 0.623 & 0.051 & 12.060 & 0.000 \\
\hline
\end{tabular}

$\mathrm{RE}$, resilience; $\mathrm{WE}$, work engagement; El, emotional intelligence.

TABLE 7: $R$-squared $\left(R^{2}\right)$.

\begin{tabular}{lcc}
\hline Variables & $\boldsymbol{R}$-square & $\boldsymbol{R}$-square adjusted \\
\hline Resilience & 0.493 & 0.489 \\
Work engagement & 0.267 & 0.264 \\
\hline
\end{tabular}

TABLE 8: Specific indirect effects (inner model).

\begin{tabular}{lcccc}
\hline Variable & $\begin{array}{c}\text { Original sample } \\
(\mathbf{0})\end{array}$ & $\begin{array}{c}\text { Standard deviation } \\
\text { (s.d.) }\end{array}$ & $\begin{array}{c}\text { T-Statistics } \\
(\mid \mathrm{O} / \mathrm{s.d.|})\end{array}$ & $\boldsymbol{p}$ \\
\hline $\mathrm{EI}->$ WE-> RES & 0.073 & 0.034 & 2.171 & 0.030 \\
\hline
\end{tabular}

$\mathrm{RE}$, resilience; $\mathrm{WE}$, work engagement; El, emotional intelligence.

Table 6 presents the path coefficients and the associated $p$ and $t$-values, which give an indication of the direction and strengths of the proposed paths. The results observe that all the paths in the theoretical model are statistically significant $p<0.05$. The pathway from emotional intelligence to resilience was the strongest $(\beta=0.619: t=12.060$ : mean $=$ 0.623: $p=0.000$ ). Emotional intelligence to work engagement observed the second strongest path $(\beta=0.516: t=11.189$ : mean 0.519: $p=0.000)$. Work engagement to resilience had the least statistically significant path $(\beta=0.142: t=2.222$ : mean $=0.139: p=0.027$ ). Table 7 shows the extent to which emotional intelligence and work engagement influences resilience. It is reported that the variables in the theoretical model (emotional intelligence and work engagement) explain approximately $49.3 \%$ of the variance in resilience, which can be interpreted as moderate, according to Chin (1998). It should be observed that both emotional intelligence and resilience have a significant association with work engagement. The results provide support for Hypothesis 1 and Hypothesis 2.

To determine whether work engagement mediates the relationship between emotional intelligence and resilience, the specific indirect effects (Table 8 ) should be consulted. 
Table 8 shows that work engagement has a significant mediating effect $(0.073, p=0.030)$ on the relationship between emotional intelligence and resilience. The results support Hypothesis 3.

\section{Discussion}

The primary objective of this study aimed to determine whether emotional intelligence and work engagement influence resilience. It was hypothesised that the two constructs positively influence work engagement (directly and indirectly) and that emotional intelligence lays the foundation for the effect of work engagement on resilience. This was based on the idea that emotionally intelligent individuals experience positive emotions. The experience of positive affect is instrumental in the development and maintenance of positive fulfilling work-related moods (Prins et al., 2018). The development of positive fulfilling workrelated moods (characteristic of work engagement) enables employees to increase their job resources and job demands. This premise is consistent with the conservation of the resources theory, which claims that personal resources have a positive impact on work engagement, which in turn reinforces personal resources (Salanova et al., 2010). It is grounded on the notion that individuals who possess personal resources are capable of gaining more resources to sustain them in times of adversity. This accumulation of resources creates resource caravans and these resource caravans result in positive outcomes, such as better coping and adaptation skills (Hakanen et al., 2008; Salanova et al., 2010). Similarly, the broaden-and-build theory posits that positive emotions trigger upward spirals, because the broadening of individual thought-action repertoires influence the building of resources, which may, in turn, promote well-being and adaptive functioning (Pidgeon et al., 2014; Tugade \& Fredrickson, 2004).

With the given background, the outcomes of the present study are discussed in the following paragraphs.

The two independent variables, emotional intelligence and work engagement, had significant relations with resilience. De Waal and Pienaar (2013) indicated that employees who are engaged are highly energetic, self-efficacious and exercise influence over events that affect their lives. The belief that they may cope with various stressors boost their confidence, which allows them to use adaptive coping strategies and endure demanding situations without being overwhelmed by the demands. Schwarzer and Warner (2013) argued that self-efficacy activates affective, motivational and behavioural mechanisms in demanding situations, which promotes resilience. Emotionally intelligent individuals have the capacity to combat emotional experiences. This capacity to manage and regulate emotions generates continued fulfilment and capacity for positive emotions (Pidgeon et al., 2014). According to the broaden-and-build theory, positive emotions broaden the scope of attention and cognition, enabling flexible and creative thinking and augmenting people's enduring coping resources in the form of resilience
(Tugade \& Fredrickson, 2004). Likewise, Çutuka and Aydoğanb (2019) argued that the experience of positive emotions builds psychological resilience over time. The results support Hypotheses 1 and 2.

The study observed that work engagement significantly mediated the relationship between emotional intelligence and resilience. However, there is only evidence of partial mediation given that the relationship between emotional intelligence and resilience is still statistically significant. Based on the conservation of resources theory, emotionally intelligent employees are capable of conserving resources because of their ability to understand their own emotions and those of others, as well as their ability to use and regulate their feelings effectively (Salanova et al., 2010). Through the ability to effectively manage their own and others' emotions, they conserve their physical and cognitive energy and remain cognitively engaged with work tasks (Antoniou \& Cooper, 2016). When individuals are cognitively engaged, they experience positive work-related moods (vigour, dedication, absorption). De Waal and Pienaar (2013) suggested employees who experience these work-related moods are highly energetic, self-efficacious and exercise control of their environment. Possessing self-efficacy and having the skill to exercise control over the environment foster resilience, as individuals will have the confidence and skill to deal with the many challenges of professional practice (Antoniou \& Cooper, 2016; Schutte \& Loi, 2014; Schwarzer \& Warner, 2013).

Emotional intelligence can therefore be used as a building block for individuals to develop positive mood and coping skills. Schutte and Loi (2014) explained that emotional selfregulation facilitates an individual's mastery of workplace events and reactions to them. In consequence, individuals are likely to experience positive outcomes such as work engagement. Van Wingerden and Poell (2019) argued that engaged employees craft their jobs to create a better suiting and more challenging work environment. Creating a resourceful and challenging work environment leads to positive outcomes such as resilience (Van Wingerden \& Poell, 2019).

An alternative explanation for the established link is that employees who can manage their emotions experience enthusiasm, meaning and satisfaction and remain strongly committed to their work (dedication) in the face of challenges (Albrecht, 2010). Dedicated individuals feel positive and according to the broaden-and-build theory (Tugade \& Fredrickson, 2004), positive emotions, such as being excited, enthusiastic and having a sense of pride, help to improve their capacity for resilience as they broaden their individual thought-action repertoires and augment personal resources that improve coping and adaptation. This suggests that work engagement via dedication explains the influence of emotional intelligence on resilience. Therefore, the third hypothesis, work engagement mediates the relationship between emotional intelligence and resilience was confirmed. 
However, although an indirect link was observed, it should be observed that the indirect effects of emotional intelligence on resilience were smaller compared with the direct effects. A plausible explanation could be that the stronger direct relationship between emotional intelligence and resilience decreased the variance in resilience that could be explained by work engagement. Emotional intelligence and resilience are both recognised as personal resources and resilience is assumed to be part of emotional intelligence, which explains the strong direct effect. The results suggest that emotional intelligence on its own can directly influence the resilience levels of nurses. Emotional intelligence enables individuals to accurately assess their environment, express empathy, think according to the priority of problems and organise thoughts, which consequently increase resilience (Magnano et al., 2016). Individuals will not be able to bounce back or engage if they do not have accurate assessment of the environment in which they are operating (Ackley, 2016; Antoniou \& Cooper, 2016). In addition, emotional intelligence is argued to predict positive active coping skills of which resilience is one (Alizadeh Goradel, Mowlaie, \& Pouresmali, 2016). The results support the relationship between emotional intelligence and resilience and strengthen previous theory and research (Prins et al., 2018) that demonstrate that emotional intelligence has a positive direct effect on resilience. Generally, these results suggest that emotional intelligence can directly influence the resilience levels of nurses.

Overall, given that emotional intelligence and work engagement have a significant impact on resilience, a theory can be framed to integrate emotional skills and work engagement dimensions as positive states and attitudes within the healthcare industry to promote resilience. Interventions aimed at raising awareness regarding resilience should focus on how to foster greater emotional intelligence, which creates a positive mindset and harmonious relationship that in turn influence positive organisational outcomes. By implementing initiatives aimed at enhancing emotional intelligence, employees may experience greater levels of resilience. Thus, to improve nurses' resilience, interventions should be focused more on emotional intelligence training. Nurses are faced with emotional, physical and psychological demands whilst at the same time having to offer quality care, given that it is imperative for the care service industry to foster high levels of resilience so that nurses can be able to cope and adapt.

\section{Limitations of the study}

The study has some limitations. Firstly, the small sample size (252) and the relatively homogenous nature of the sample. The participants were predominantly female nurses with very few male nurses working at three hospitals in the Mangaung Metropole: Botshabelo, Pelonomi and National. If the findings are to be representative of the total workforce, quantitative studies similar to this study should be conducted with more than 252 participants, bearing in mind the large number of nurses in public hospitals.
Secondly, the study relied on a cross-sectional survey design, making it difficult to prove causal relationships between the variables. Thirdly, self-administered questionnaires could influence the reliability and validity of the data and findings. Self-reported data can lead to response bias such as social desirability bias. The use of paper-based self-administered questionnaires may give rise to impression management, which can be seen as a weakness of self-administered questionnaires. Fourthly, and related to the above limitation, the language used in the questionnaire could also have been a limitation. The questionnaire was only provided in English. Some of the Afrikaans and Sesotho-speaking nurses found some of the items difficult to understand, especially words such as 'immersed' and 'determined' in the UWES and RES. Respondents failed to interpret certain items that were most confusing to them, for example, item 11 of the UWES, 'I am immersed in my work'.

\section{Practical implications and recommendations}

Emotional intelligence and work engagement were observed to have predictive values for resilience. Therefore, institutions should carefully adopt and implement programmes or initiatives to address this relationship. The South African healthcare industry is faced with a number of challenges that require nurses' resilience to cope with the demands and challenges. The growing COVID-19 pandemic has placed unexpected demands on the nurses. The unaffordable services offered by private hospitals has also resulted in the larger part of the population seeking help from the public hospitals, further increasing the demands on the professional nurses. This has negatively impacted the physical and mental well-being of nurses, making resilience critically important as a coping mechanism. Emotional intelligence was observed to have a higher predictive value and a strong relationship with resilience. In the light of these findings and in order to improve nurses' resilience, more focus should be on understanding the power of emotions and how it leads to self-directed learning. Cultivating emotional intelligence competencies, such as self-awareness, social awareness, self and relationship management, recognition of emotions and regulation of emotions can be used as building blocks for coping and adaptation. The emotional intelligence of nurses can be improved through a number of ways - this may include identifying negative thoughts, emotions and expressions, evaluating individual actions, behaviours and relationships, expressing feelings and focusing on resolving conflict through communication (Chowdhury, 2020). More importantly, for nurses, practicing empathy should be a daily habit. Listening to a patient without judging or accepting harsh words from someone under stress can significantly increase emotional and social intelligence, thereby strengthening resilience through strong social bonds.

Emotional intelligence through self-directed learning assists in stress management, adapting to change and providing flexible problem-solving techniques. High stress tolerance and impulse control positively influence resilience, which leads to efficiency. Enhancing emotional intelligence amongst 
nurses therefore improves their work-life balance, enhances their relationships with patients and colleagues and creates optimistic feelings for the patients they interact with. Strategies aimed at increasing emotional intelligence may include taking interpersonal skills courses, doing an emotional intelligence test to understand self-awareness, performing regular self-directed learning activities and participating in coaching. In addition, networking with others to improve job-related skills and seeking feedback from peers, family and even patients may also lead to improved emotional intelligence. The implementation of these strategies may foster emotional intelligence and result in positive outcomes for nurses, which, in turn, will influence resilience.

It is recommended that the role of emotional intelligence and work engagement as routes towards being resilient be considered and investigated further. Future studies should focus on additional variables, such as mindfulness and job crafting as mediating variables between emotional intelligence and resilience. The sample comprised 252 nurses, predominantly women, from selected public hospitals. Future research should use a randomised sampling process with larger samples and should also include more male nurses.

\section{Conclusion}

The purpose of this survey was to investigate the effect of emotional intelligence and work engagement on resilience. The empirical statistical effect of emotional intelligence and work engagement on resilience observed in the study provided new understanding with respect to employee resilience. This study concludes that both emotional intelligence and work engagement are important in explaining an employee's resilience. However, the strong direct link between emotional intelligence and resilience is very interesting. This strongly suggests that emotional intelligence should be the main focus in the promotion of resilience amongst nurses in the workplace.

\section{Acknowledgements Competing interests}

The authors declare that they have no financial or personal relationships that may have inappropriately influenced them in writing this article.

\section{Authors' contributions}

P.C. and M.H. contributed equally to the design and implementation of the research, to the analysis of the results and to the writing of the manuscript.

\section{Funding information}

This research received no specific grant from any funding agency in the public, commercial or not-for-profit sectors.

\section{Data availability}

Data that support the findings of this study can be made available upon reasonable request from the corresponding author M.H.

\section{Disclaimer}

The views and opinions expressed in this article are those of the authors and do not necessarily reflect the official policy or position of any affiliated agency of the authors.

\section{References}

Ackley, D. (2016). Emotional intelligence: A practical review of models, measures, and applications. Consulting Psychology Journal: Practice and Research, 68(4), 269286. https://doi.org/10.1037/cpb0000070

Aiena, B., Baczwaski, B.J., Schulenberg, S., \& Buchanan, E. (2014). Measuring resilience with the RS-14: A tale of two samples. Journal of Personality Assessment, 97(3), 1-10. https://doi.org/10.1080/00223891.2014.951445

Albrecht, S.L. (2010). Handbook of employee engagement: Perspectives, issues, research and practice. Cheltenham: Edward Elgar Publishing Limited.

Alizadeh Goradel, J., Mowlaie, M., \& Pouresmali, A. (2016). The role of emotional intelligence, and positive and negative affect on the resilience of primiparous women. Journal of Fundamentals of Mental Health, 18(5), 243-248.

Antoniou, A.S., \& Cooper, C.L. (2016). Copying, personality and the workplace: Responding to psychological crisis and critical events. London: Gower Publishing.

Best, C. (2019). Building resilience in contemporary nursing practice. Nursing Practice, 30(8), 400-404. https://doi.org/10.12968/pnur.2019.30.8.400

Bakker, A.B., \& Leiter, M. (2010). A handbook of essential theory and research. In A.B. Bakker \& M.P. Leiter (Ed.), Work engagement: A handbook of essential theory and research. New York, NY: Psychology Press.

Çam, O., \& Buyukbayram, A. (2017). Nurses' resilience and effective factors. Journal of Psychiatric Nursing, 118-126. https://doi.org/10.14744/phd.2017.75436

Chin, W.W. (1998). The partial least squares approach to structural equation modeling In G.A. Marcoulides (Ed.), Modern methods for business research (pp. 295-336). Mahwah, NJ: Lawrence Erlbaum Associates.

Chowdhury, M.R. (2020). How to improve emotional intelligence through training. Positive Psychology. Retrieved from https://positivepsychology.com/emotionalintelligence-training

Crane, M.F. (2017). Managing for resilience: A practical guide for employee wellbeing and organizational performance. New York, NY: Routledge.

Çutuka, Z.A., \& Aydoğanb, R. (2019). Emotional self-efficacy, resilience and psychological vulnerability: A structural equality modeling study. Journal of Educational Sciences and Psychology, 9(1), 106-114.

De Waal, J.J., \& Pienaar, J. (2013). Towards understanding causality between work engagement and psychological capital. SA Journal of Industrial Psychology, 39(2), 1-10. https://doi.org/10.4102/sajip.v39i2.1113

Duncan, D. (2020). What the COVID-19 pandemic tells us about the need to develop resilience in the nursing workforce. Nursing Management, 27(3), 22-27. https:// doi.org/10.7748/nm.2020.e1933

Goleman, D. (1995), Emotional intelligence. New York, NY: Bantum Books.

Hair, J.F., Risher, J.J., Sarstedt, M., \& Ringle, C.M. (2019). When to use and how to report the results of PLS-SEM. European Business Review, 31(1), 2-24. https://doi. org/10.1108/EBR-11-2018-0203

Hakanen, J.J., Perhoniemi, R., \& Toppinen-Tanner, S. (2008). Positive gain spirals at work: From job resources to work engagement, personal initiative and work-unit innovativeness. Journal of Vocational Behaviour, 73(1), 78-91. https://doi. org/10.1016/j.jvb.2008.01.003

Hart, P., Brannan, J.D., \& Chesnay, M.D. (2014). Resilience in nurses: An integrative review. Journal of Nursing Management, 22(6), 720-734. https://doi. org/10.1111/j.1365-2834.2012.01485.x

Hobfoll, S.E., Stevens, N.R., \& Zalta, A.K. (2015). Expanding the science of resilience: Conserving resources in the aid of adaptation, psychological inquiry. An International Journal for the Advancement of Psychological Theory, 26(2), 174180. https://doi.org/10.1080/1047840X.2015.1002377

Kašpárková, L., Vaculík, M., Procházk, J., \& Schaufeli, W.B. (2018). Why resilient workers perform better: The roles of job satisfaction and work engagement. Journal of Workplace Behavioural Health, 33(1), 43-62. https://doi.org/10.1080/ 15555240.2018.1441719

Khamisa, N., Peltzer, K., Ilic, D., \& Oldenburg, B. (2017). Effect of personal and work stress on burnout, job satisfaction and general health of hospital nurses in South Africa. Health SA Gesondheid, 22, 252-258. https://doi.org/10.1016/j.hsag.2016.10.001

Koen, M.P., Van Eeden, C., \& Wissing, M.P. (2011). The prevalence of resilience in a group of professional nurses. Health SA Gesondheid, 16(1), 1-11. https://doi. org/10.4102/hsag.v16i1.576 
Magnano, P., Craparo, G., \& Paolillo, A. (2016). Resilience and emotional intelligence: Which role in achievement motivation. International Journal of Psychology research, 9(1), 9-20. https://doi.org/10.21500/20112084.2096

McDermid, F., Peters, K., Daly, J., \& Jackson, D. (2016). Developing resilience: Stories from novice academics. Nurse Education Today, 38, 29-35. https://doi. org/10.1016/j.nedt.2016.01.002

Meintjes, A., \& Hofmeyr, K. (2018). The impact of resilience and perceived organisational support on employee engagement in a competitive sales environment. SA Journal of Human Resource Management, 16(1), e1-e11. https://doi.org/10.4102/sajhrm.v16i0.953

Nel, P., Du Plessis, M., \& Bosman, L. (2015). Comparing different versions of the questionnaire in a South African context. South African Journal of Industrial Psychology, 41(1), 1-9. https://doi.org/10.4102/sajip.v41i1.1220

Pallant, J. (2013). SPSS survival manual. New York, NY: Two Pen Plaza.

Paul, H., Bamel, U., \& Garg, P. (2016). Employee resilience and OCB: Mediating effects of organizational commitment. Vikalpa: The Journal for Decision Makers, 41(4), 308-324. https://doi.org/10.1177/0256090916672765

Pidgeon, A.M., Ford, L., \& Klaassen, F. (2014). Evaluating the effectiveness of enhancing resilience in human service professionals using a retreat-based mindfulness with Metta training program: A randomised control trial. Psychology, Health \& Medicine, 19(3), 355-364. https://doi.org/10.1080/13548506.2013.806815

Prins, A., Van Niekerk, E., \& Weyers, A. (2018). Emotional intelligence: Tipping point in workplace excellence. Randburg: KR Publishing.

Rahim, M.A., Psenicka, C., Polychroniou, P., Zhao, J.-H., Yu, C.-S., Chan, K.A., \& Van Wyk, R. (2002). A model of emotional intelligence and conflict management strategies: A study in seven countries. International Journal of Organizational Analysis, 10(4), 302-326. https://doi.org/10.1108/eb028955

Ramalisa, R.J., Du Plessis, E., \& Koen, M.P. (2018). Increasing coping and strengthening resilience in nurses providing mental health care: Empirica qualitative research. Health SA Gesondheid, 23(0), 1-9. https://doi.org/10.4102/ hsag.v23i0.1094

Rich, B.L., Lepine, J.A., \& Crawford, E.R. (2010). Job engagement: Antecedents and effects on job performance. Academy of Management Journal, 53(3), 617-635. https://doi.org/10.5465/amj.2010.51468988

Salanova, M., Schaufeli, W.B., Xanthopoulou, D., \& Bakker, A.B. (2010). The gain spiral of resources and work engagement: Sustaining a positive worklife. In A.B. Bakker \& M.P. Leiter (Ed.), Work engagement: A handbook of essential theory and research (pp. 118-131). New York, NY: Psychology Press.

Salilih, S.Z., \& Abajobir, A.A. (2014). Work-related stress and associated factors among nurses working in public hospitals of Addis Ababa, Ethiopia: A cross-sectional study. Workplace Health \& Safety, 62(8), 326-332. https://doi.org/10.3928/2165079920140708-02
Schaufeli, W.B., \& Bakker, A.B (2004). UWES Utrecht work engagement scale: Preliminary manual (measuring instrument). Utrecht: Utrecht University, Occupational Health Psychology Unit.

Schaufeli, W.B., Salanova, M., González-Romá, V., \& Bakker, A.B. (2002). The measurement of engagement and burnout: A two-sample confirmatory factor analytic approach. Journal of Happiness Studies, 3, 71-93. https://doi. org/10.1023/A:1015630930326

Schutte, N.S., \& Loi, N.M. (2014). Connections between emotional intelligence and workplace flourishing. Personality and Individual Differences, 66, 134-139. https://doi.org/10.1016/j.paid.2014.03.031

Schwarzer, R., \& Warner, L.M. (2013). Perceived self-efficacy and its relationship to resilience. In Resilience in children, adolescents, and adults (pp. 139-150). New York, NY: Springer.

Simons, J.C., \& Buitendach, J.H. (2013). Psychological capital, work engagement and organisational commitment amongst call centre employees in South Africa. South African Journal of Industrial Psychology, 39(2), 12. https://doi.org/10.4102/sajip. v39i2.1071

Toyama, H., \& Mauno, S. (2017). Associations of trait emotional intelligence with social support, work engagement, and creativity in Japanese eldercare nurses. Japanese Psychological Research, 59(1), 14-25. https://doi.org/10.1111/jpr.12139

Truter, E., Theron, L., \& Fouché, A. (2014). Indicators of resilience in resilient South African designated social workers: Professional perspectives. The Social Work Practitioner-Researcher, 26(3), 305-329.

Tugade, M.M., \& Fredrickson, B.L. (2004). Resilient individuals use positive emotions to bounce back from negative emotional experiences. Journal of Personality and Social Psychology, 86(2), 320-333. https://doi.org/10.1037/ 0022-3514.86.2.320

Van Wingerden, J., \& Poell, R.F. (2019). Meaningful work and resilience among teachers: The mediating role of work engagement and job crafting. PLoS One, 14(9), e0222518. https://doi.org/10.1371/journal.pone.0222518

Wagnild, G.M., \& Collins, J. (2009). Assessing resilience. Journal of Psychosocia Nursing, 47(12), 28-33. https://doi.org/10.3928/02793695-20091103-01

Wagnild, G.M., \& Young, H.M. (1993). Development and psychometric psychometric evaluation of the resilience scale. Journal of Nursing Management, 1(2), 165-178.

Yilmaz, E.B. (2017). Resilience as a strategy for struggling against challenges related to the nursing profession. Chinese Nursing Research, 4, 9-13. https://doi. org/10.25164/cnr201701003

Zhu, Y., Zhang, S., \& Shen, Y. (2019). Humble leadership and employee resilience: Exploring the mediating mechanism of work-related promotion focus and perceived insider identity. Frontiers in Psychology, 10(673), 1-9. https://doi. org/10.3389/fpsyg.2019.00673 